\title{
ENROLLING HABITS IN HIGHER EDUCATION. WHAT SOURCES OF INFORMATION DO STUDENTS HAVE AND WHAT ARE MISSING?
}

\author{
N. Rivas ${ }^{1}$, J. Minguillón ${ }^{1}$, J. Chacón ${ }^{2}$ \\ ${ }^{1}$ Universitat Oberta de Catalunya (SPAIN) \\ ${ }^{2}$ Elisava (SPAIN)
}

\begin{abstract}
Since the appearance of the web, universities have changed the way education is designed and provided. Nowadays, most universities offer online programmes and subjects, and there are even fully online open/distance universities. Students now have a higher degree of flexibility, which allows them to choose among an endless list of subjects for completing their degree. Although this can be seen as a success of enrollment flexibility measures, it may be also the source of one of the most well-known problems in open education: high dropout rates, partly caused by inadequate enrollment. Students may face an overwhelming amount of information they are not able to sort, or they may even find it insufficient to plan and select subjects strategically. Understanding students' habits when enrolling is important to improve their learning experience. In order to do so, a questionnaire about enrollment habits was sent to students taking a Computer Engineering degree in their first or second semester. Results show that, although the majority of students are quite satisfied with the enrollment process, there is still room for improvement. Surprisingly, tutors' recommendations are not as relevant as institutional web pages as an information source. An exploratory factor analysis shows that the most important factor for students to determine their enrollment is the time they have to study, followed by their experience in previous semesters. Responses to the questionnaire were used to design a preliminary sketch of an interactive web application that addresses students' needs and habits.
\end{abstract}

Keywords: Enrollment, higher education, learning analytics, learning dashboards, data visualisation.

\section{INTRODUCTION}

Higher education institutions have embraced the web and this fact has changed the way education is provided. Nowadays, most universities offer blended or online courses as part of their e-learning strategy. The result is an incredible increase in the number of online educational websites and technology-based educational scenarios [1]. Most institutions provide students (and teachers) with a virtual learning environment where they can interact with other peers, digital resources and services. These scenarios generate an immense amount of data that can be gathered, processed and then visualised in order to better understand learner's behaviour $[2,3]$. When students interact with digital services, resources and other users in a virtual learning environment, they generate a digital trace that can be captured and stored in order to be further analysed, taking into account relevant evidencebased data $[4,5]$. Researchers have always been aware of the potential of this data $[1,6,7]$. As a natural evolution from a data-based perspective to an intervention-based one, the concept of learning analytics has emerged, in order to study how to analyze, understand and improve Technology Enhanced Learning scenarios [1, 8].

Nowadays, most universities offer online programs and courses, and some of them are fully online. As enrollment data is available, we can objectively measure enrollment flexibility using institutional data. For instance, in the semester 2019/1, more than 37,000 students took at least one subject from one official degree at the Universitat Oberta de Catalunya (UOC), from a catalogue of almost 1,800 subjects scattered in 28 degrees (in two different languages). Most of these 37,000 students enrolled into one up to five different subjects, generating more than 24,000 different enrollment patterns, following a long-tail distribution, where most enrollment patterns were just taken by only one student. Although this diversity could be seen as a success of the enrollment flexibility measures in open universities, it may be also the source of two well-known problems in open education: firstly, and the most important, dropout rates tend to be higher, especially in the first semester, as stated in [9]. Students may not consider the magnitude of workload and the required depth of their involvement in the online courses as reasonable criteria to make the decision to study online. Selecting the appropriate subjects is crucial to adjusting such workload. Secondly, this high enrollment variability 
makes semester planning at the institutional level a very difficult task, which also justifies the analysis proposed in this paper.

Understanding such an amount of enrollment data needs it to be displayed in a comprehensive way, that is why researchers and institutions recently started to use data visualisations. Despite the pioneer ideas described by Duval [7], this is a rather new research field [10], and learning dashboards seem to be struggling in finding the right indicators taking into account different users, defining the student learning gains and creating specific data visualisations for education [3]. Therefore, the use of learning dashboards for analysing and visualising enrollment data may be an interesting research line, as it might provide a better understanding of the reasons behind the enrollment decisions taken by students that will later impact their learning experience.

As any learning analytics tool that meets students' needs, the first thing that comes to mind is to know such student needs $[11,12]$. The inclusion of stakeholders early on the development of learning analytics dashboards can help designers and developers identify expectations in order to improve satisfaction. Without the stakeholder implication it is possible that most design decisions tend to be only based on the institutional managers' expectations and beliefs [13], and do not include the plurality of student expectations and needs [14]. The same data may not be meaningful in the same way to students, tutors or administrators and, therefore, educational researchers need to select metrics that are understandable and useful to the target audience [15]. The current big challenge is to choose the right metrics to show and to incorporate students' perspectives into the learning dashboard design.

Following the ideas presented in the above mentioned works, we believe that a visualisation tool could help students' during enrollment. In order to design such a tool, a questionnaire could help us to find the proper metrics to show, understand the information needs of students and find out about their preferences. Other projects involving learning dashboards have also used questionnaires before creating and evaluating an artefact. For example, in [16], Corrin and de Barbra found out that there was diversity in participants' strategies and ability to interpret the feedback through the analysis of the questionnaire data. In [17], Park and Jo investigated how students perceive needs in regard to a learning dashboard by performing a series of interviews and then testing their prototype. A series of questionnaires was conducted in order to understand students conformity, perceived usefulness as well as opinions and suggestions.

\section{METHODOLOGY}

In order to understand the way students enroll, first we analyzed the current enrollment process. Second, we analyzed how they use it. We measured students' usage of the institutional website by looking at Google Analytics data. Finally, through the questionnaire, we gathered additional information about students' enrollment habits.

\subsection{Current enrollment process}

Table 1 describes the steps the students take to enroll at UOC, see [18] for further information. Students have two main sources of information: the institutional website and their tutor. The enrollment process is fully online and students are completely autonomous upon enrollment.

Table 1. Typical students steps when enrolling.

\begin{tabular}{|l|l|l|l|}
\hline Step 1 & Step 2 & Step 3 & Step 4 \\
\hline $\begin{array}{l}\text { Visit the degree landing page and look at } \\
\text { different pages. }\end{array}$ & $\begin{array}{l}\text { Ask for access } \\
\text { and } \\
\text { information. }\end{array}$ & $\begin{array}{l}\text { Log into the } \\
\text { "welcome } \\
\text { campus". }\end{array}$ & $\begin{array}{l}\text { Select how } \\
\text { many and which } \\
\text { subjects. }\end{array}$ \\
\hline$\underline{\text { https://estudios.uoc.edu/es/grados/ingenieria- }}$ & $\begin{array}{l}\text { Registration } \\
\text { form with basic } \\
\text { student's data. }\end{array}$ & $\begin{array}{l}\text { Further } \\
\text { information is } \\
\text { provided by } \\
\text { tutors through } \\
\text { such space. }\end{array}$ & $\begin{array}{l}\text { Student } \\
\text { dialogues with } \\
\text { the tutor to } \\
\text { determine } \\
\text { enrollment. }\end{array}$ \\
\hline
\end{tabular}




\subsection{Preliminary analysis}

In summary, the following data was extracted from Google Analytics. This information helped us to better understand how students were using the current enrollment process:

- Potential students spend most of their time in the web pages describing the degree organization, such as: https://estudios.uoc.edu/es/grados/ingenieria-informatica/plan-estudios.

- Such pages are also the most important in the different browsing routes that students take before asking for access and information.

- These pages are the ones that have more time on site and a lower bounce rate.

Therefore, degree semestral organization is the students' starting point before deciding how many and which subjects they want to enroll into.

\subsection{Questionnaire design}

Based on the belief that students need to be the center of the learning dashboard design, and in order to create a useful tool, we created a questionnaire that attempts to provide further information from the enrollment process besides the one that we have already gathered from Google Analytics and our expertise; to help us understand the preferences of potential students regarding the display of information when enrolling; and to discover any other issue we were not taking into account.

The purpose of the questionnaire was to understand student preferences [19] for obtaining information about the Computer Engineering degree that, if offered prior to enrollment, it would support their subject enrollment decisions [20]. The questionnaire was merely exploratory and the first step of a whole User Experience process, following a design-based methodology. Specifically, we were interested in generating a list of possible descriptive topics that students felt would be most helpful when enrolling, the role of validations and different information sources, different factors that make students choose the total number of subjects or specific subjects, students motivations to learn and their overall opinion on the enrollment process.

First, we asked about their motivations to choose the Computer Engineering degree (Q1) and exploring students current situation, so we asked about how many semesters they have been enrolled (Q2), how many subjects they have enrolled during their last semester (Q3), their validated subjects (Q4) and the information sources they have used in order to determine their last enrollment (Q5, containing 4 items). Second, we asked about factors that were important to students in order to determine the total number of subjects (Q6, 7 items), to choose each subject in particular (Q7, 12 items) and factors that could be helpful when selecting subjects (Q8, 8 items). Finally, we asked students about their satisfaction with the enrollment process (Q9), including an open question about any other information they might be interested to share with us (Q10). The complete questionnaire, its questions and items can be found in the following link: https://visualenrolment.com/enrolling-habitsquestionnaire.pdf

\subsection{Sample and data collection}

The questionnaire was sent to all students taking a Computer Engineering degree in their first or second semester at the UOC. We used Qualtrics as it is integrated into the institutional information systems for gathering data from students. An email containing a personalized (and anonymized) link to the questionnaire was sent to each student, followed by a reminder six days later. The questionnaire was available online for a total of 12 days.

Additional information from the institutional learning record store [4] was also available for the participating students, namely gender, age group, relative semester, and previous studies' level. Table 2 summarizes population demographics. Notice that most students were men (typical of any computer science or engineering degree), and older than traditional brick-and-mortar universities (mean=30.7 years old, $s d=8.5$ ). Approximately half of them had previous higher education experience. 
Table 2. Demographics of students participating in the online questionnaire.

\begin{tabular}{l|l|r|r}
\hline \hline Gender & Female & 191 & $13.2 \%$ \\
& Male & 1,261 & $86.8 \%$ \\
\hline Age group & $<=20$ years old & 61 & $4.2 \%$ \\
& $21-30$ years old & 776 & $53.4 \%$ \\
& $31-40$ years old & 382 & $26.3 \%$ \\
& $>40$ years old & 233 & $16.1 \%$ \\
\hline Relative semester & First & 763 & $52.5 \%$ \\
& Second & 689 & $47.5 \%$ \\
\hline Previous studies & Special access & 47 & $3.2 \%$ \\
& First degree & 630 & $43.4 \%$ \\
& Initiated degree & 579 & $39.9 \%$ \\
& Finished degree & 196 & $13.5 \%$ \\
\hline Total & & 1,452 & $100.0 \%$ \\
\hline \hline
\end{tabular}

\section{RESULTS}

The questionnaire was sent to 1,452 students and 229 responses were received. Incomplete or negative answers (first question was willing to participate in the survey) were removed, leaving 184 responses for analysis purposes (response rate was $12.7 \%$ ). Sampling error at a $95 \%$ confidence level and maximum uncertainty $(p=q=0.5)$ was $6.75 \%$. Responses were weighted according to gender, age group and number of semesters, in order to reflect the targeted student demographics using the Survey $\mathrm{R}$ package [21]. As some responses had missing values, we used multiple imputation implemented by the MICE algorithm [22].

Regarding the number of subjects, as expected in a distance university, most students were only enrolled into two $(41.7 \%)$ or three $(24.8 \%)$ subjects, followed by only one subject $(12.5 \%)$ and four, five or six or more subjects $(21.0 \%)$, as shown in Table 3 . Any recommendation system should take this fact into account, discouraging students from enrolling in too many subjects, specially in their first semesters, when they are still learning to become online learners [23], and need to evaluate their capabilities. Table 3 also summarizes the number of subjects according to students' demographics. No significant differences between men and women were found. Younger students were found to enroll in more subjects, and this fact was also consistent among age groups. Students in their second semester enrolled in more subjects than new students, probably because they were using their acquired (successful) experience from the previous semester. Finally, regarding their previous studies, no significant differences were found, although students with previous university experience (partial or completed) enroll in less subjects.

Regarding the recognition of previous studies, Table 3 shows that most students (85.6\%) had one or more subjects that they want to be recognized and incorporated into their academic record (that is validated). On the other hand, students without validated subjects enrolled in more subjects, while students that had not decided it yet enrolled in less subjects. This data shows that previous studies are a key factor when deciding the final number of subjects to enroll.

Regarding the reasons for taking a degree (students could select up to two of them), most students said it was for professional reasons $(39.1 \%)$, while only a few said it was for personal reasons only $(23.3 \%)$, and the remaining (37.6\%) selected both possibilities. Notice that professional reasons had a positive impact on the number of enrolled subjects, as students had probably the need to obtain the degree as soon as possible for advancing in their career. 
Table 3. Number of enrolled subjects according to weighted participants' demographics.

\begin{tabular}{l|l|r|r|r}
\hline \hline & Weighted \% & $\begin{array}{r}\text { Number of subjects } \\
\text { Mean (SD) }\end{array}$ & $\begin{array}{r}\text { Kruskal- } \\
\text { Wallis test }\end{array}$ \\
\hline Gender & Female & $13.4 \%$ & $2.51(1.30)$ & 1.0345 \\
& Male & $86.6 \%$ & $2.71(1.22)$ & $\mathrm{p}=0.3023$ \\
\hline Age group & $<=20$ years old & $2.4 \%$ & $4.00(0.99)$ & 62.69 \\
& $21-30$ years old & $54.4 \%$ & $2.89(1.34)$ & $\mathrm{p}<0.001$ \\
& $31-40$ years old & $26.8 \%$ & $2.36(0.86)$ & \\
& $>40$ years old & $16.4 \%$ & $2.33(1.15)$ & \\
\hline Relative semester & First & $51.6 \%$ & $2.44(1.06)$ & 2.3761 \\
& Second & $48.4 \%$ & $2.94(1.35)$ & $\mathrm{p}=0.01854$ \\
\hline Previous studies & Special access & $6.1 \%$ & $2.91(1.04)$ & 2.143 \\
& First degree & $43.9 \%$ & $2.61(1.13)$ & $\mathrm{p}=0.5446$ \\
& Initiated degree & $35.0 \%$ & $2.80(1.38)$ & \\
& Finished degree & $15.0 \%$ & $2.52(1.25)$ & \\
\hline Validated subjects & None & $14.4 \%$ & $3.35(1.25)$ & 13.312 \\
& Pending & $42.0 \%$ & $2.36(0.87)$ & $\mathrm{p}=0.001626$ \\
& Requested & $43.6 \%$ & $2.77(1.42)$ & \\
\hline Reasons & Personal & $23.3 \%$ & $2.60(1.18)$ & 6.11 \\
& Professional & $39.1 \%$ & $3.09(1.27)$ & $\mathrm{p}=0.04956$ \\
& Both & $37.6 \%$ & $2.52(1.23)$ & \\
\hline \hline Total & & $100.0 \%$ & $2.68(1.23)$ & \\
\hline \hline
\end{tabular}

\subsection{Item analysis}

First, we analysed $\mathrm{Q} 5$, regarding the sources of information used by students to determine their enrollment. Surprisingly, tutors were not considered the most valuable resource $(3.59, S D=0.11)$, but the information available in the institutional website $(4.18, S D=0.09)$. For exploratory purposes we computed the difference among both items, which ranges from -4 (tutors preferred) to 4 (website preferred), and compared it among groups. Table 4 shows these and other relevant factors according to such groups. Notice that students which pursue professional goals, younger or with no validated subjects are less satisfied with tutors, as well as students that already have a degree.

Second, we analysed Q6, regarding the reasons for determining the total number of subjects. The available time for studying was the most important item for students, followed by the difficulty of the subjects. Time and difficulty were, therefore, the main reasons for determining the total number of subjects selected. Then we analysed Q7, in order to know why students choose each subject. Passed and validated subjects were the most important items, followed by the knowledge that students have (or think they have) about the curriculum of each subject. Students seemed less interested in subject methodology or if the subject was an innovative topic in the field. Q8 was about other information that could help students choose each subject. This information is available through the institutional LRS [4] but students do not have access to it. The most important item was the availability of the subject calendar, followed by the number of learning activities and subject difficulty. Again, we can see how time and difficulty are the most relevant topics for students.

An overall satisfaction indicator about the enrollment process (Q9) was also analyzed. In general, students were mostly satisfied $(7.90$ out of $10, S D=1.84)$, although some differences were found 
among groups. Younger students, students with a previously initiated degree and students with more validated subjects are more satisfied than the rest.

Table 4. Most interesting items and factors according to weighted participants' demographics.

\begin{tabular}{l|l|r|r|r|r|r}
\hline \hline & & Web -Tutors & Satisfaction & F1 Difficulty & F2 Tutors & F3 Interests \\
\hline Gender & Female & 0.31 & 7.68 & 3.09 & 3.48 & 3.52 \\
& Male & 0.63 & 7.93 & 2.85 & 3.41 & 3.28 \\
\hline Age & $<=20$ years old & 0.97 & 8.18 & 3.69 & 3.05 & 3.34 \\
group & $21-30$ years old & 0.61 & 8.02 & 2.90 & 3.35 & 3.27 \\
& $31-40$ years old & 0.59 & 7.78 & 2.99 & 3.60 & 3.50 \\
& $>40$ years old & 0.44 & 7.67 & 2.53 & 3.42 & 3.15 \\
\hline Relative & First & 0.43 & 7.87 & 2.90 & 3.63 & 3.32 \\
semester & Second & 0.74 & 7.93 & 2.87 & 3.20 & 3.31 \\
\hline \multirow{2}{*}{ Previous } & Special access & 0.59 & 7.82 & 2.24 & 3.62 & 2.97 \\
studies & First degree & 0.35 & 7.73 & 2.89 & 3.57 & 3.28 \\
& Initiated degree & 0.43 & $\mathbf{8 . 4 4}$ & 3.10 & 3.53 & 3.47 \\
& Finished degree & $\mathbf{1 . 6 3}$ & $\mathbf{7 . 1 8}$ & 2.63 & $\mathbf{2 . 6 4}$ & 3.21 \\
\hline \multirow{2}{*}{ Validated } & None & $\mathbf{1 . 0 9}$ & 7.79 & 3.07 & 3.28 & 3.30 \\
subjects & Pending & 0.49 & 7.23 & 2.71 & 3.33 & 3.24 \\
& Requested & 0.50 & 8.10 & 2.99 & 3.56 & 3.39 \\
\hline Reasons & Personal & 0.58 & 7.97 & 2.90 & 3.35 & 3.42 \\
& Professional & $\mathbf{0 . 9 9}$ & 7.42 & 2.93 & 3.23 & 3.26 \\
& Both & 0.33 & 8.12 & 2.84 & 3.61 & 3.24 \\
\hline \multirow{2}{*}{ Total } & & 0.58 & 7.90 & 2.88 & 3.42 & 3.32 \\
\hline \hline
\end{tabular}

\subsection{Exploratory factor analysis}

We used exploratory factor analysis as a method for rough exploration of item correlations and main topics. Using the weighted covariance matrix, we computed the overall $\mathrm{KMO}$ index for all the questionnaire items described in Table 4 , obtaining $\mathrm{KMO}=0.79$, which is reasonable as stated by Kaiser. One of the items had a low index $\left(\mathrm{Q} 6 \_1, \mathrm{KMO}=0.46\right)$, so it was removed. A total of 8 factors were found to be meaningful, according to three different criteria: eigenvalues, parallel analysis and optimal coordinates [24]. Although 8 factors may seem too many for so few answers obtained, they might provide interesting clues about students' habits. These factors explained $55.8 \%$ of the total variance, as follows (we used a cutoff threshold of 0.5 to avoid items shared by more than one factor):

- F1: items Q8_2, Q8_3 and Q8_4. This is a measure about how students perceive the difficulty of a given subject.

- F2: Q5_2, Q6_3 and Q7_1. The support received from tutors during enrollment.

- F3: Q6_7, Q7_2, Q7_3 and Q7_12. Personal and professional interests in certain subjects or topics.

- F4: Q5_4, Q7_6, Q7_7. Previous knowledge and competencies.

- F5: Q7_9 and Q7_10. Subject design methodology.

- F6: Q6_4, Q7 5. Experience from the previous semester.

- F7: Q8_5, Q8_6 and Q8_7. Satisfaction and subject calendar.

- F8: Q7_4. Degree semestral organization. 
The most interesting factors are F1, F2 and F3, shown in Table 4. Younger and special access studies seem to be concerned about subject difficulty. Younger and finished degree students rely more on the website as an information source and less in tutors. Special access students care less about their interests in certain subjects or topics. Factors from F4 to F8 reflect other interesting topics, but do not show conclusive results.

\subsection{Open questions}

We also inspected the answers to the open question (Q10). In summary, most of the answers talked about time and difficulty of the subjects, total enrollment prices and validations. Some of the answers were really interesting and provided ideas that could be incorporated to the learning dashboard design. For example, some students were interested in having a section where they could see and understand their degree path and the previous knowledge requisites. Some students also asked about previous subjects needed in order to enroll in a new one. They were also interested in knowing the subject calendar, so they could arrange their schedule for the semester.

\section{DISCUSSION}

\subsection{Limitations}

Before proceeding with discussion, we would like to address the questionnaire limitations. The main limitation of this questionnaire is its target population. All respondents were current students at UOC's Computer Engineering degree in their first or second semester. Due to the nature of UOC students, enrollment factors may differ from other online student populations. Therefore, the resulting data might not generalise to other universities. Response rate was not very high, although this might have been caused because data was collected in the middle of the coronavirus pandemic. As the total number of responses was not very high, the results of the exploratory analysis must be taken cautiously.

\subsection{Relevant factors}

Due to lack of space, we will only discuss the factors related to time and tutors. One of the most remarkable results that will require further study is the relationship between the students and tutors during enrollment. Students from different categories (younger, finished degrees, students that do not require subject validations or that have a professional interest in the field) seemed to rely more on the website information than on tutors. As stated by Schumacher, students' self-regulation is considered a key factor for success in higher education [11]. Nevertheless, tutors interventions when enrolling need to be addressed. The analysis of data gathered in the questionnaire has made us question if the tool to be developed should only focus on students or could also become a support tool for tutors, in order to improve their interventions [25]. Furthermore, tutors do not have control over the information shown in the institutional website. Results for this study will be addressed with tutors and another questionnaire should be performed in order to find out more about this second stakeholder [13].

On the other hand, time management seems to be the most important factor for students, followed by their experience with subjects in their last semester. As for the information they will find interesting in order to choose each subject, the availability of the schedule of activities and tests seem to be their preferred information. Therefore, time should play an important role in the design of the learning dashboard [26]. Online higher education students receive information in different formats and at different times. This can cause time management issues, so the new tool must help students in establishing strategies to better manage their time. [27]

\subsection{Implications for designing}

In the light of these results, we propose to take into account the following premises:

- The number of subjects shown must be different depending on the student's available time. Therefore, a selector must be added.

- Previous experience in the degree is important. Validated or pending validation, passed and failed subjects must be present in the design. 
- Some sort of time measurement should be present in the design. Preferably, the calendar of each subject would also appear, if possible.

- Other important factors for students such as costs, difficulty, prior knowledge or satisfaction should also be present in the design. If possible, these factors should be presented to students interactively.

\subsection{First proposal}

Based on the abovementioned implications, a first sketch of the tool has been designed. We were strongly inspired by the OECD Better Life Index [27]. Nevertheless, this is merely a preliminary sketch and further development is required in order to prepare its final design.

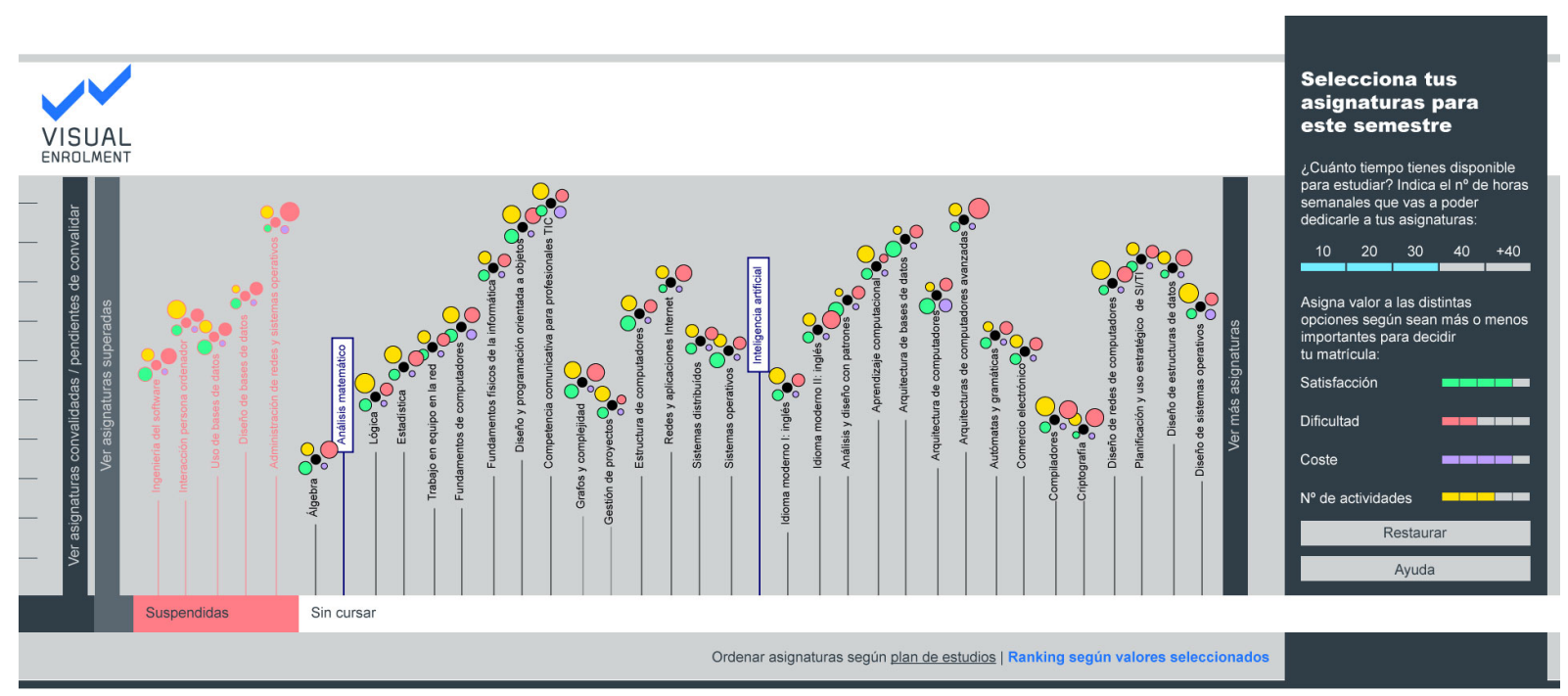

Tu progreso general: Vista de grado
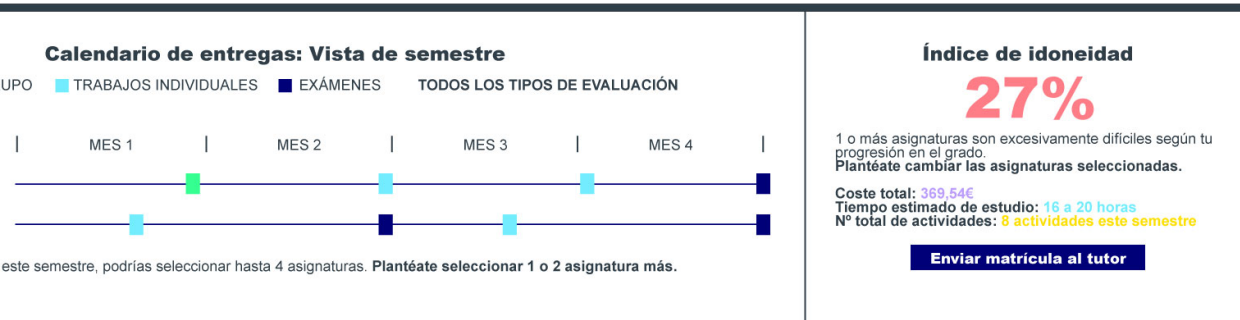

Figure 1. Fist Sketch of the future learning dashboard.

In this first proposal, students can visualize all subjects from their degree: validated, passed, failed (i.e. pending) and not yet taken (also pending). Students also have to select the number of hours they have available to study, and the tool will let them select only the total number of subjects they can take. Other visualization elements have been added: satisfaction, difficulty, costs and total number of activities. Students can sort the subjects according to the selected values. Finally, a general progress bar for the grade, subject schedules and an enrollment suitability index have also been added. This way, students can see the amount of credits completed so far, the approximate delivery for subject tasks and if their enrollment is suitable in respect to the subjects they have selected.

\subsection{Conclusions}

Enrollment in open and distance universities is the first decision students must face in each academic semester. Some students make wrong choices when selecting subjects, probably because they are overwhelmed by the large amount of available information, which is mostly static and in textual or tabular form. In order to design a data visualization tool that responds to students' needs during enrollment, we created a questionnaire to better understand students' habits and decision-making, including how they decide how many and which subjects they enroll into, their sources of information and the relevant factors. The gathered answers provided us with further knowledge about the 
enrollment process, complementing the current students' informational habits extracted from different digital metrics. Questions related to available time, semestral organization and subject characteristics seem to be very interesting to students. Unfortunately, some of this information is not currently available through the institutional website supporting the enrollment process.

Based on such findings, we presented a preliminary proposal for the design and implementation of an enrollment interactive tool (implemented as a learning dashboard), which will be further developed taking into account two issues. First, as the number of answers was limited, a second version of the questionnaire will be performed, in order to validate the most important factors provided by students' responses and open questions. Second, the unexpected fact that tutors were considered less valuable than the information available in the institutional website deserves also further research, in order to extend the proposed learning dashboard as a tool used not only by students but with their tutors altogether, as a dialogue space to provide better support during enrollment.

\section{REFERENCES}

[1] T. Elias, "Learning Analytics: The Definitions, the Processes, and the Potential," 2011.

[2] W. Greller and H. Drachsler, "Translating learning into numbers: A generic framework for learning analytics," Educ. Technol. Soc., vol. 15, no. 3, pp. 42-57, 2012.

[3] B. A. Schwendimann et al., "Perceiving learning at a glance: A systematic literature review of learning dashboard research," IEEE Transactions on Learning Technologies, vol. 10, no. 1. Institute of Electrical and Electronics Engineers, pp. 30-41, 2017.

[4] J. Minguillón, J. Conesa, M. E. Rodríguez, and F. Santanach, "Learning analytics in practice: Providing E-learning researchers and practitioners with activity data," Lect. Notes Educ. Technol., pp. 145-167, 2018.

[5] K. Sin and L. Muthu, "APPLICATION OF BIG DATA IN EDUCATION DATA MINING AND LEARNING ANALYTICS - A LITERATURE REVIEW," ICTACT J. Soft Comput., vol. 05, no. 04, pp. 1035-1049, 2015.

[6] C. Romero and S. Ventura, "Educational data mining: A survey from 1995 to 2005," Expert Syst. Appl., vol. 33, no. 1, pp. 135-146, Jul. 2007.

[7] E. Duval, "Attention please! Learning analytics for visualization and recommendation," in ACM International Conference Proceeding Series, 2011, pp. 9-17.

[8] G. Siemens, "Learning Analytics," Am. Behav. Sci., vol. 57, no. 10, pp. 1380-1400, 2013.

[9] P. Bawa, "Retention in Online Courses: Exploring Issues and Solutions-A Literature Review," SAGE Open, vol. 6, no. 1, 2016.

[10] K. Verbert et al., "Learning dashboards: An overview and future research opportunities," Pers. Ubiquitous Comput., vol. 18, no. 6, pp. 1499-1514, 2014.

[11] C. Schumacher and D. Ifenthaler, "Features students really expect from learning analytics," Comput. Human Behav., vol. 78, pp. 397-407, Jan. 2018.

[12] A. Marengo, A. Pagano, and A. Barbone, "Adaptive learning: A new approach in student modeling," in Proceedings of the International Conference on Information Technology Interfaces, ITI, 2012, pp. 217-221.

[13] A. Whitelock-Wainwright, D. Gašević, R. Tejeiro, Y. S. Tsai, and K. Bennett, "The Student Expectations of Learning Analytics Questionnaire," J. Comput. Assist. Learn., vol. 35, no. 5, pp. 633-666, Oct. 2019.

[14] S. Slade and P. Prinsloo, "Learning Analytics: Ethical Issues and Dilemmas," Am. Behav. Sci., vol. 57, no. 10, pp. 1510-1529, 2013. 
[15] A. Wise, Y. Zhao, and S. Hausknecht, "Learning Analytics for Online Discussions: Embedded and Extracted Approaches," J. Learn. Anal., vol. 1, no. 2, pp. 48-71, 2014.

[16] L. Corrin and P. De Barba, "How do students interpret feedback delivered via dashboards?," in ACM International Conference Proceeding Series, 2015, vol. 16-20-Marc, pp. 430-431.

[17] Y. Park and I. H. Jo, "Development of the learning analytics dashboard to support students' learning performance," J. Univers. Comput. Sci., vol. 21, no. 1, pp. 110-133, 2015.

[18] A. Sangrà, "A new learning model for the information and knowledge society: The case of the UOC," Int. Rev. Res. Open Distance Learn., vol. 2, no. 2, pp. 152-167, Jan. 2002.

[19] I. Hilliger et al., "For learners, with learners: Identifying indicators for an academic advising dashboard for students," in Lecture Notes in Computer Science (including subseries Lecture Notes in Artificial Intelligence and Lecture Notes in Bioinformatics), 2020, vol. 12315 LNCS, pp. 117-130.

[20] J. Marshall, H. Greenberg, and P. A. Machun, "How would they choose? Online student preferences for advance course information," Open Learn., vol. 27, no. 3, pp. 249-263, Nov. 2012

[21] T. Lumley, "Analysis of complex survey samples," Journal of Statistical Software, vol. 9, no. 1. pp. 1-19, 2004.

[22] S. van Buuren and K. Groothuis-Oudshoorn, "mice: Multivariate imputation by chained equations in R," J. Stat. Softw., vol. 45, no. 3, pp. 1-67, 2011.

[23] K. Lee, H. Choi, and Y. H. Cho, "Becoming a competent self: A developmental process of adult distance learning," Internet High. Educ., vol. 41, pp. 25-33, Apr. 2019.

[24] G. Raiche and D. Magis, "nFactors: Parallel Analysis and Other Non Graphical Solutions to the Cattell Scree Test," R Packag. version 2.4.1, 2020.

[25] O. Simpson, "The impact on retention of interventions to support distance learning students," Open Learn., vol. 19, no. 1, pp. 79-95, 2004.

[26] B. Tabuenca, M. Kalz, H. Drachsler, and M. Specht, "Time will tell: The role of mobile learning analytics in self-regulated learning," Comput. Educ., vol. 89, pp. 53-74, Nov. 2015.

[27] L. Song, E. S. Singleton, J. R. Hill, and M. H. Koh, "Improving online learning: Student perceptions of useful and challenging characteristics," Internet High. Educ., vol. 7, no. 1, pp. 59-70, Jan. 2004.

[28] "OECD Better Life Index." [Online]. Available: http://www.oecdbetterlifeindex.org/. [Accessed: 11-Jan-2021]. 